\title{
Summary of discussion at the Seminar
}

\author{
Lene Mikkelsen \\ ECE Statistical Division, Palais des Nations, 1211 Geneva 10, Switzerland
}

\section{Introduction}

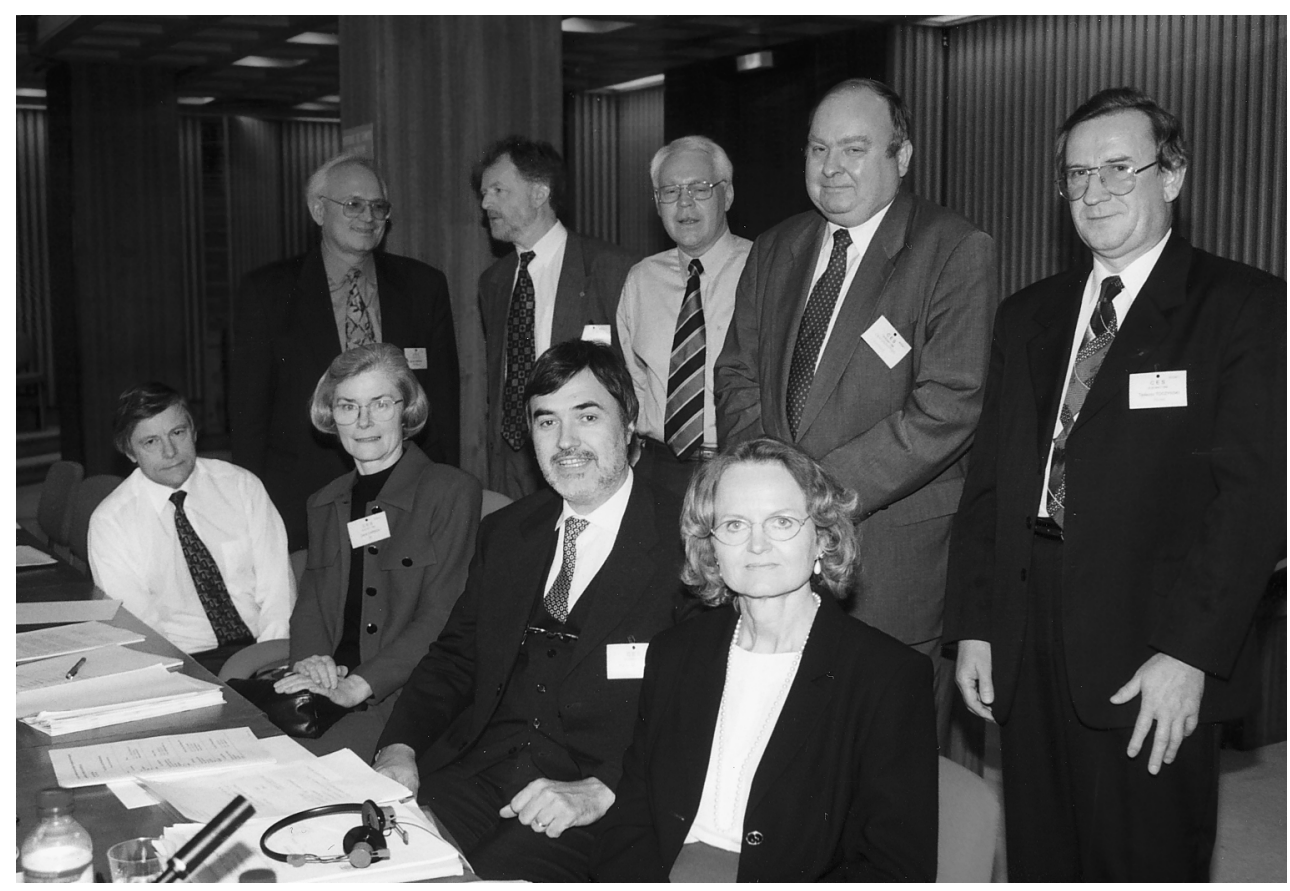

Contributors to the seminar of the 1998 CES plenary. Back right to left: Mr. Toczyński (Poland), Mr. Christophersen (European Commission), Mr. Snorrason (Iceland), Mr. Longva (Norway) and Mr. Brüngger (Switzerland). Front right to left: Ms Mikkelsen (UN/ECE), Mr. Garonna (Italy), Ms Carson (IMF) and Mr. Holt (UK).

The session was organized and chaired by Mr. Snorrason, Iceland, who had chosen four themes to cover the topic of this year's seminar:

1. Relationship between governments and NSOs valued in terms of the Fundamental Principles

2. Constraints caused by the administrative use of statistics 
3. Role of international agencies, heads of NSOs and the community of official statisticians in promoting and monitoring good practices at the national level

4. International statistical agencies and the Fundamental Principles

All themes were covered in the five papers the session organizer had invited ${ }^{1}$. As a further basis for discussion, nine countries, Armenia, Azerbaijan, Canada, Finland, France, Hungary, Slovenia, South Africa, The former Yugoslav Republic of Macedonia, contributed supporting papers which threw additional light on the often complex relationship between Statistical Offices and Government. The invited papers were presented by their authors while the supporting papers were introduced by Mr. Snorrason.

\section{Relationship between Governments and NSOs Valued in Terms of the Fundamental Principles}

The keynote speaker, Mr. Christophersen, talked about the complex relationship that exists between statistical offices and the government and gave illustrations of how difficult it can be to combine political needs with the independence and professional freedom of a statistical service. Because part of the work of a statistical office serves a political purpose, even definitions, nomenclatures and methodologies sometimes have to be adjusted to meet policy requirements. He concluded, however, that in spite of these well-known constraints it was still possible for statistical offices to maintain professional independence and public credibility.

Mr. Christophersen considered that the statistical services of every country should be an independent administrative body that is outside direct control of the government. The independence should be enshrined in the national statistical legislation and safeguarded the same way as the independence of the judicial system and the central bank. He proposed that one way of resisting political pressure would be to have heads of the national statistical offices appointed by the government for a non-renewable term of 8-10 years. The achievement and maintenance of the status of a statistical office is dependent on the professional quality of its products and on the integrity of its management, both of which he felt could be strengthened by having regular evaluations by a scientific council of the office's work program. He also discussed the need for financial independence of statistical offices and suggested that in order to ensure independence and stability regular appropriations to the statistical office might be fixed in relation to some indepen-

1 - Relations between statistical offices and governments: the implications for statistics of administrative use and needs, by Henning Christophersen (CES/1998/18)

- The relationship between government and the national statistical institute, by Tadeusz Toczyński (CES/ 1998/19)

- The Fundamental Principles and the impact of using statistics for administrative purposes, by Tim Holt (CES/1998/20)

- The relationship between government and the national statistical institute: fostering the Fundamental Principles of Official Statistics, by Carol Carson (CES/1998/21)

- International principles governing official statistics at the national level: are they relevant for the statistical work of the international organisations as well?, by Heinrich Brüngger and Svein Longva (CES/ 1998/22) 
dent aggregate, such as GDP or total budget outlays. Finally, to further ensure the independence of statistical services, in case of dispute with the government, they should be able to settle their dispute in the judiciary system.

Mr. Toczyński addressed the same theme, but from the viewpoint of a country undergoing social, political and economic transition. Among the questions he raised was whether their statistical laws are able to provide sufficient support for official statistics to allow them to provide objective and reliable information, respect data confidentiality and give all users equal access simultaneously to all users as required by the law. He also discussed the major hazards and preconditions which underlie the transformation of statistics in transition countries and described the social context, notably the statistical education which is needed and the creation of a category of professional statisticians as opposed to government statisticians. In his conclusions, he queried whether countries which are in a period of social and economic transition can be expected to implement the full scope of the Fundamental Principles. He therefore proposed that it may be useful to make them operational at particular stages of statistical development and that outside assistance should be given to these countries in transforming their official statistics so that they fully become part of the democratic information system.

In introducing the supporting papers, the chairperson mentioned that many of the papers from the newly independent countries described their new statistical independence and in doing so stressed the importance of the statistical laws which had been introduced as a result of their statistical reform process. He concluded though that despite such legislation and all the hard work to reform, the overall picture could be illusionary and that the practical reality could still be lagging behind.

A vivid discussion on what constituted independence for a statistical office followed and there was general agreement that the legislative dimension was far from being sufficient. Other essential pillars were "externalization/transparency" of the statistical process, including the ways it is practiced; "standing/reputation" in form of scientific and personal integrity of the head and the service; and finally the "administrative arrangement" and environment the office operates under.

These were seen as the main pillars from which a statistical office draws its authority and independence. It was further mentioned that "independence" is more a cultural arrangement than a legalistic one and that it is something one needs to continually work at and earn. It was also recognized that to achieve absolute credibility, a statistical office needs to release data simultaneously to government and the public according to a pre-published schedule.

At the same time, it was generally accepted that the independence of statistical offices is not absolute. Every office operates within an administrative arrangement which is culturally dependent and every office is constrained by political and legislative considerations. Moreover, as it was pointed out with government being the main statistical client as well as having influence on the financial resources of the statistical office, some agreement has to be worked out which can be accepted by both sides.

The greater importance of the legal status for countries which have not historically been democracies was discussed. It was said that the low image of the civil 
service in some transition countries have forced them to depend more than other countries on having a legal framework to operate within. Everyone is dependent on the circumstances they live under and, as the UK representative reminded the meeting, once the office is in system which functions well and everyone works within it, there seems to be no need of having it anymore.

From what was said in the discussion, it can be concluded that the independence of statistical services may be enshrined in the national statistical legislation, but that it also is culturally related and that practical independence has more dimensions to it which are earned through hard work, integrity, transparency and accountability.

\section{Constraints Caused by the Administrative Use of Statistics}

The impact of using statistics for administrative purposes was particularly discussed in Mr. Holt's paper. In presenting his paper, Mr. Holt reminded the meeting that governments use statistics in two main ways: (i) to inform, monitor and evaluate public policy and, (ii) the direct use of statistics for administrative purposes. He emphasized that while it was up to the policy makers to decide on how to use the statistics, it was the role of the statistical office to ensure that the statistics provided were of impartial and high quality. Unfortunately, the public does not always distinguish between the two processes and the statistical output is often seen as the direct cause of the policy action. Hence, when the public is disenchanted with a particular administrative process, the statisticians, as producers of the data, are often criticized.

Several other speakers noted the administrative use of statistics and mentioned examples of uses such as the use of population statistics for allocation of resources between regions, electoral boundaries, economic convergence criteria for entering the EMU, price indices for pensions, etc. Although the administrative use of statistics need not always give rise to tension, it was observed that because of the political impact of these type of statistics, the temptation for interference is higher and the statistical office needs to draw heavily on factors strengthening their statistical integrity and pay even more attention than usual to the quality of the data they produce. Therefore, when compiling such statistics, statistical offices should try to externalize any problem encountered and endeavor to engage users, experts and the statistical community as much as possible. Special reference was made to the CPI because of the high political interest concerned with its use. It was agreed that international collaboration and support among CPI statisticians could help maintain the statistical integrity of national consumer price indices in case of political interference.

The discussion also underlined that the administrative use of statistics can give rise to difficult borderlines between what affects the individual and what is for the public good. For example, with the aim of promoting greater public accountability and educational choice school league tables are produced in the UK which identify individual institutions. This would normally not be an acceptable use of confidential administrative data, but in this case the tables were prepared with the agreement of the schools for the benefit of the public. 


\section{Role of International Agencies, Heads of NSOs and the Community of Official Statisticians in Promoting and Monitoring Good Practices at the National Level}

No one disputed that the Fundamental Principles, which the Conference of European Statisticians adopted in 1991, are still valid and up-to-date, but the discussion revealed that some felt that it would be useful to make them more operational and to transform the ideals into institutional realities. Perhaps, as it was suggested by Mr. Toczyński, they should also be adapted to different stages of development and some monitoring mechanism should be worked out for them.

In presenting her paper, Ms Carson of the IMF, thought it important that the fostering of the Fundamental Principles be done in a global context and all producers of statistics be included, not only national statistical offices. This view was supported by many speakers. As examples of their use by various international bodies she mentioned Eurostat's Basic Regulation, IMF's data dissemination standards and OECD's use of the Fundamental Principles to assess the statistical systems of countries applying for membership.

Ms Carson also made a number of proposals for how the principles could be promoted. The suggestion of creating an Internet-based Fundamental Principles Reference Site received a lot of support. Currently meetings are the only vehicles for offices to share experiences, whereas an Internet site would be globally accessible for everyone working in statistics. United Nations Statistics Division came out as a strong supporter of this and wanted as many countries as well as regional commissions involved in the discussion of what are good practices. The meeting was reminded that a similar process had been used for the Guidelines on Technical Cooperation. It was further suggested that this Internet site should be linked to the World Electronic Statistical Platform (WESP) currently being set-up by the UNSD and that it should be managed by the UN/ECE.

The Irish representative informed the meeting that although they had practiced the individual principles for close to half a century, they were not complacent about them and had distributed the Fundamental Principles widely in the office as well as putting them on their Web site. They are also published in some of their publications in an Annex.

There was agreement, though, that it was not sufficient to publicize the principles for statisticians. Ministries, politicians, central banks and others concerned with statistics need to be even more informed and convinced of the importance of statistical integrity.

Another proposal made by Ms Carson concerned the monitoring of how the principles were practiced at the national level. A process leading to accrediting national offices was outlined. The process was similar to the peer review system used in a several ECE countries for the accreditation of universities and other educational institutions. 


\section{International Statistical Agencies and the Fundamental Principles}

The topic of whether the Fundamental Principles are relevant for the statistical work of international organizations was discussed in the paper by Brünger and Longva. Mr. Brüngger told the meeting that although international organizations do not usually collect personal data, confidential information of another type is still sometimes collected for the work of the secretariat and the collective product is only released with the agreement of countries. Moreover, due to the substantial amount of value added to some data, it is arguable whether certain international organizations can be considered as mere re-disseminators of national figures rather than as producers of data. It is also a fact that there is a growing demand for internationally comparable data for decision making, and therefore the products of international organizations have a far greater impact today than when they started their work.

Mr. Brüngger further pointed out that if the production and dissemination process of international comparable statistics increasingly will be seen as a separate product line, which national and international actors contribute to, then, clearly, there ought to be an overall quality and credibility label attached to such products. Consequently, national and international actors have to adhere to the same basic principles as regards quality and integrity, which is not currently always the case.

In concluding, he argued that the operational framework of the national and international organizations needs to be brought closer together. He therefore made some practical proposals to move this forward and pointed out the risk of taking no action, which, he said, would be the disappearance of the notion of "official statistics" and statistical compartmentalization at the international level.

The meeting recognized that the paper raised several fundamental questions that deserved to be answered but which could not be given justice in the remaining time.

Mr. Habermann pointed out that data collection, production and dissemination are only one part of the work of an international statistical office. The statistical improvement work that is done is as important and, moreover, is an activity that can only be done by international offices.

Illustrating it with an example of how several international agencies had entered the local debate about the quality of statistical indicators in South Africa, Mr. Orkin suggested that considerations of statistical accountability, transparency and professionalism - as embodied in the Fundamental Principles - should also be developed for activities of the international organizations. This would ensure the separation of responsibilities for description and analysis from the policy activities they undertake. He therefore suggested that a consultative process in the international statistical community, similar to that which yielded the Fundamental Principles, should be undertaken and that it might yield some additional principles concerning the international organizations.

In concluding the discussion, Mr. Snorrason reminded the meeting that at the beginning when the Fundamental Principles were drafted, they were mainly seen as being for the newly independent countries. This attitude, he said, had changed as it has become apparent that the Fundamental Principles have fostered a com- 
mon understanding and raised consciousness, even in the well-established countries, about the importance of statistical integrity, transparency and independence. There was general recognition that the Fundamental Principles had been much more valuable than could have been foreseen back in 1991 .

Lene Mikkelsen is Teamleader in the UN/ECE Statistical Division 